\title{
LETRAMENTO AUDIOVISUAL E EDUCAÇÃO DO CAMPO: REFLEXÕES SOBRE UM PERCURSO FORMATIVO NA LEDOC/UNB
}

\author{
AUDIOVISUAL LITERACY AND RURAL EDUCATION: REFLECTIONS ON A \\ FORMATIVE PATHWAY AT LEDOC/ UNB
}

Felipe Canova Gonçalves ${ }^{1}$

\begin{abstract}
Resumo: Este artigo analisa possibilidades de letramento audiovisual na Educação do Campo, tomando como objeto de análise um percurso formativo em audiovisual realizado durante dois anos na Licenciatura em Educação do Campo da UnB (LEdoC/UnB). A partir da análise de relatórios e depoimentos de participantes sistematizados no processo, buscamos refletir sobre a dimensão metodológica do projeto e seus resultados, mantendo a ênfase nos aspectos pedagógico-formativos com a linguagem audiovisual e os diferentes caminhos para o trabalho com múltiplos letramentos.
\end{abstract}

Palavras-chave: Letramento audiovisual; Educação do Campo; formação de professores.

\begin{abstract}
This paper analyzes the possibilities of audiovisual literacy in Rural Education, taking as an object of analysis a formative pathway in audiovisual carried out during two years in the Undergraduate course in Rural Education at the University of Brasília (LEdoC/UnB). From the analysis of reports and testimonies of participants systematized in the process, we seek to reflect on the methodological dimension of the project and its results, maintaining the emphasis on pedagogical-formative aspects with the audiovisual language and the different paths for working with multiple literacies.
\end{abstract}

Keywords: Audiovisual literacy; Rural Education; teacher education.

Quando pensamos o audiovisual e sua relação com a educação, surgem vários caminhos nas pesquisas acadêmicas e nas práticas pedagógicas de ensino-aprendizagem: linguagem artística, ferramenta pedagógica, modalidade de letramento, tecnologia da informação e comunicação (TIC), instrumento de visibilidade e reconhecimento da escola e, principalmente, de seus sujeitos. Especificamente na relação do audiovisual com a Educação do Campo percebemos, a partir das experiências e concepções para o trabalho com esta linguagem que emergem do pouco mais de uma década de implementação de cursos de licenciatura e dos princípios norteadores da Educação do Campo, um diálogo com o nexo histórico das experiências de articulação entre movimentos sociais, educação popular, linguagens artísticas e a comunicação popular, em que a arte, a comunicação e a educação têm estado conectadas à formação política e a organização social.

Um dos marcos iniciais deste debate sobre audiovisual na Educação do Campo está sistematizado nos textos introdutórios do livro Outras Terras à Vista: cinema e educação do campo (MARTINS et al., 2010). Em linhas gerais, apontou-se a necessidade de articular as dimensões da exibição/debate em sala de aula com a produção de audiovisual, superando um uso instrumental limitado ao conteúdo das obras. Para essa superação, segundo os autores, é "fundamental que a escola trabalhe com o letramento na esfera do audiovisual se tem como objetivo a formação de indivíduos críticos e capazes de tomar decisões e distinguir com autonomia os diversos significados de uma obra ou de um discurso" (MARTINS et al., 2010, p. 14), entendendo o sentido social das estruturas formais de obras audiovisuais. Refletir sobre as possibilidades de realização desse letramento é nosso objeto de pesquisa neste artigo, a partir

\footnotetext{
${ }^{1}$ Universidade de Brasília, Brasília, DF, Brasil.
} 
de uma experiência concreta em um curso de licenciatura em Educação do Campo. Sendo assim, realizamos a descrição e a análise, neste artigo, de um percurso em letramento audiovisual realizado durante dois anos na Licenciatura em Educação do Campo da UnB (LEdoC/UnB), buscando refletir sobre sua dimensão processual e seus resultados, porém mantendo a ênfase nos aspectos pedagógico-formativos com a linguagem audiovisual.

\section{Análise de um percurso em letramento audiovisual}

A percepção de que a linguagem audiovisual e as TIC devem ser apropriadas pela Licenciatura em Educação do Campo, fazendo parte do cotidiano do curso, motivou um grupo de professores da UnB a inscreverem um projeto no edital "Apoio à capacitação no uso das Tecnologias da Informação e Comunicação para a juventude rural”, chamada pública $\mathrm{n}^{\circ}$ 01/2011 da Secretaria de Inclusão Digital (SID) do Ministério das Comunicações (MC) em parceria com a Secretaria Nacional de Juventude (SNJ), vinculada à Secretaria Geral da Presidência da República (SGPR) do então primeiro governo de Dilma Rousseff (2011-2014).

A existência de uma linha temática para as TIC direcionadas à Educação do Campo no referido edital contemplou na UnB as iniciativas de formação já em andamento nas áreas de comunicação digital, bem como no campo estético/artístico das linguagens. Criou-se, então, um desenho institucional com a articulação de diferentes projetos e iniciativas acadêmicas da universidade em torno da proposta intitulada "Formação de Educadores do Campo para o uso de Tecnologias de Informação e Comunicação, para análise e produção audiovisual e trabalho com a juventude rural do Centro-Oeste", contemplada no edital com 200 mil reais para iniciar o projeto em fevereiro de 2012. Faziam parte deste projeto: o Centro Transdisciplinar de Educação do Campo e Desenvolvimento Rural (CTEC), o Projeto de Extensão Terra em Cena, o Laboratório de Educação e Comunicação Comunitária (Lecom), todos do campus UnB Planaltina; o Programa de Extensão Comunicação Comunitária (ComCom), da Faculdade de Comunicação, campus UnB Darcy Ribeiro; e as Casas Digitais, implementadas para acesso à internet e formação nos territórios de atuação da $\mathrm{LEdoC} / \mathrm{UnB}^{2}$.

Feita a organização do grupo de professores e técnicos participantes, definiram-se os objetivos da iniciativa que, de acordo com o projeto enviado ao Ministério das Comunicações, eram: a) formar estudantes da LEdoC/UnB no uso das TIC, tendo como enfoque promover a "capacidade de análise crítica das formas hegemônicas de representação da realidade e capacidade técnica de produção e ensino no campo do audiovisual e do domínio das TIC, para seu uso nas escolas do campo" (UNIVERSIDADE DE BRASÍLIA, 2011, p. 18); b) realizar oficinas de formação na linguagem audiovisual nos territórios de origem e atuação dos estudantes vinculados ao projeto, priorizando a juventude do entorno das Escolas do Campo destas localidades; c) formar estudantes para atuar como multiplicadores nas Casas Digitais, consolidando-as como espaços educativos e culturais nas comunidades. Como público-alvo direto, delimitou-se as(os) educadoras(es) das quatro turmas então em andamento na LEdoC/UnB, e como indireto as comunidades de assentamentos e quilombolas de origem dos estudantes, bem como as escolas do campo destes territórios, numa estimativa total de público de duas mil pessoas beneficiadas.

A metodologia do projeto estruturou-se em torno da pedagogia da alternância, que ocupa centralidade na Educação do Campo, sobretudo na formação docente das licenciaturas envolvendo dois tempos: as atividades de Tempo Universidade (TU), nas quais os participantes permaneciam durante etapas de aproximadamente dois meses na UnB Planaltina recebendo as

\footnotetext{
${ }^{2}$ A descrição de cada uma das iniciativas citadas, bem como uma análise mais detalhada deste percurso audiovisual pode ser encontrada em Gonçalves, 2019.
} 
capacitações dos professores formadores e as orientações da coordenação do projeto ${ }^{3}$, e Tempo Comunidade (TC), quando os alunos estavam em suas comunidades de origem, para as quais levavam materiais pedagógicos e equipamentos, recebendo acompanhamento técnico e pedagógico da equipe de professores e bolsistas.

Durante o TU, um conjunto de componentes curriculares tiveram como proposta fornecerem a fundamentação teórica e de análise em audiovisual, associadas ao entendimento dos conflitos latentes nos territórios e sua contextualização histórica. Ou seja, os componentes da área de linguagens na LEdoC/UnB, que partem da crítica materialista da arte, somaram-se ao componente curricular Conflitos Estruturais Brasileiros e Educação Popular, em que o enfoque pedagógico volta-se para a "análise das relações de poder e das formas de discriminação contemporâneas, em perspectiva histórica e cultural; o estudo dos conceitos de classe, etnia, raça e gênero; e a análise dos entrelaçamentos das formas de discriminação contemporâneas" (VILLAS BÔAS, 2011, p. 318). Estabeleceu-se, portanto, nesta formação em TU uma associação produtiva entre linguagens artísticas e os conflitos estruturais no campo brasileiro em uma perspectiva histórico-social, colocando em articulação as noções de estética e política, bem como suas mediações.

Por sua vez, no TC, três frentes foram elencadas:

a. Consolidação das Casas Digitais e processos associados (portal eletrônico, redes sociais, etc.);

b. Espaço de exibição audiovisual visando a análise crítica da linguagem do cinema e da televisão, a reflexão sobre o modo como o audiovisual é trabalhado nas escolas, bem como sobre a forma como o mundo rural em si é caracterizado nas distintas plataformas audiovisuais;

c. Produção audiovisual norteada pela demanda de diagnóstico dos problemas socioambientais das comunidades rurais visando a intervenção em caráter transformador (UNIVERSIDADE DE BRASÍLIA, 2011, p. 20).

Como vemos nos itens "b" e "c", ao conciliar as esferas da análise, da produção e da exibição de audiovisual, o projeto estabeleceu um entendimento da linguagem audiovisual para além de uma dinâmica formação-oficinas-produto no audiovisual. Ou seja, colocou-se a apropriação da linguagem como um processo de pesquisa e como ponto de apoio à práxis investigativa da $\mathrm{LEdoC/UnB}$, estendendo essa dinâmica às escolas do campo e às comunidades de inserção. Aos participantes, alguns já professores nas escolas e outros futuros docentes, cabia de acordo com o projeto a tarefa de serem "protagonistas do processo de transferência de conhecimento e mediação da relação dos sujeitos do campo com o mundo das novas tecnologias de comunicação" (UNIVERSIDADE DE BRASÍLIA, 2011, p. 17).

Ambos os tempos, com seus aportes e planejamentos, possuíam avanços e limites. Um avanço era a proposição no TU de uma formação do olhar dos participantes, associando estética e política, arte e os dilemas de cada território. Trata-se de uma concepção que aproxima os estudos nos componentes curriculares da realidade social e da vida dos estudantes, mostrandose coerente com os propósitos da Educação do Campo e a necessidade de uma intervenção

\footnotetext{
${ }^{3}$ Composta pelos seguintes membros/funções conforme o relatório final do projeto: Prof. Dr. Rafael Litvin Villas Bôas/Coordenador geral; Prof. Dr. Marcelo Ximenes Aguiar Bizerril/Coordenação pedagógica e documentarista; Prof. Dra. Monica Castagna Molina/Coordenação pedagógica; Prof. Dra. Eliete Ávila Wolff/Coordenação pedagógica; Adriana Gomes/Documentarista e coordenadora de produção; Webson Dias/Documentarista e coordenador de logística dos equipamentos; Eloisa Assunção Lopes/Mestranda e coordenação pedagógica. Todos os membros estavam vinculados à Faculdade UnB Planaltina, com exceção de Eloisa, que fazia o mestrado em Ensino de Ciências no Instituto de Química (UnB) (WOLFF et al., 2013).
} 
destes alunos nos seus territórios, fomentando assim a atuação no TC. Contudo, é fundamental reconhecer também o limite dessa formação no TU, entendendo-a como um processo de sensibilização para o trabalho com as linguagens, seja pelo caráter introdutório e concentrado em carga horária limitada na universidade, como também por outro limite, diretamente relacionado às necessidades de formação deste projeto, que era a ausência de uma entrada de maior fôlego na linguagem audiovisual nos referidos componentes. Em outras palavras, formulando os limites como pergunta: como dar o passo adiante desta sensibilização inicial para um letramento audiovisual efetivo, juntando essa formação própria do olhar da Educação do Campo com a apropriação da estética e da técnica próprias da linguagem audiovisual?

Essa conexão entre teoria e prática envolvendo a apropriação da linguagem audiovisual em sintonia com a especificidade de cada comunidade de inserção foi realizada por meio da execução de dez oficinas de audiovisual em TC, ministradas pelos documentaristas Adriana Gomes, Marcelo Bizerril e Webson Dias, com apoio da coordenação pedagógica e dos bolsistas do projeto. Somou-se a este esforço um acompanhamento pedagógico com reuniões mensais de toda a equipe, sistematizado de forma constante em relatórios e textos - que inclusive fundamentam este artigo. Sobre as oficinas, um de seus aspectos mais interessantes foi a busca criativa por uma formação em audiovisual adequada ao projeto, sem uma concepção previamente concebida a ser aplicada. Cabe ressaltar também que, embora não fosse diretamente uma das metas do projeto, a equipe assumiu como objetivo a realização de vídeos das comunidades de inserção enquanto um momento potencializador da transferência dos meios de produção audiovisuais aos grupos locais, configurando uma das frentes de atuação no TC e gerando um processo formativo com um resultado final a ser exibido na Faculdade UnB Planaltina e nas comunidades, bem como ser divulgado via internet.

A compreensão do processo pedagógico das oficinas passava pelo conhecimento integral do processo de realização audiovisual e de metodologias de exibição pelos participantes do projeto, considerando os limites de tempo disponíveis para a formação. Simultaneamente, a equipe teve como objetivo construir junto aos jovens o pertencimento ao coletivo de audiovisual de cada comunidade - que envolvia o trabalho em torno da realização do filme - e o uso qualificado dos equipamentos disponíveis, adquiridos com os recursos do projeto. Também era objetivo da formação em TC ampliar a sensibilização estética voltada ao audiovisual iniciada em TU. Para tanto, a equipe de formação experimentou diferentes metodologias com os participantes como, por exemplo, a análise de trechos de filmes de referência, exercícios de enquadramento, experimentos de produção coletiva - sejam vídeos curtos de animação editados em algum software de manejo simples ou propostas iniciais de roteiro para os filmes - e o encaminhamento de estudos e tarefas para os estudantes atuarem nas suas comunidades. A ida da equipe de formadores do projeto aos assentamentos e comunidades quilombolas permitiu reconhecer, de forma inequívoca, a abertura dos moradores à iniciativa, bem como a vontade comum a vários participantes de contar a história do seu lugar, a partir de seu próprio ponto de vista, abordando nessa narrativa audiovisual as questões e os conflitos mais candentes de cada localidade.

Duas soluções criadas pelos formadores nos chamaram a atenção na análise do percurso: a criação de uma metodologia para o trabalho com a exibição de filmes nas comunidades com um enfoque mais preciso nos tempos da pedagogia da alternância e o detalhamento nas formações locais de um trabalho com roteiro. Vejamos esses dois pontos com maior detalhe, pois nos interessam especialmente por sua perspectiva de múltiplos letramentos.

Quanto ao trabalho com a exibição de filmes, a equipe do projeto organizou uma prática pedagógica de multiletramentos (ROJO, 2009): kits de DVDs foram gravados e distribuídos, acompanhados de textos de referência voltados à Educação do Campo (publicados em MARTINS et al., 2010). Os filmes selecionados eram voltados para dois âmbitos: uma seleção 
com obras de referência para os realizadores de audiovisual e outra seleção voltada para a exibição nas comunidades. Com estas exibições, propostas para algum espaço comunitário e também para a escola em acordo com os professores, almejava-se a formação como multiplicadores dos estudantes vinculados ao projeto e o estímulo ao maior pertencimento da juventude local à realização dos filmes nas comunidades. Os bolsistas multiplicadores redigiam um texto reflexivo com o retorno das atividades, no qual sistematizavam as questões que se destacaram no debate, os aspectos mais interessantes do ponto de vista da linguagem em cada filme e as razões destas escolhas, bem como as conexões entre as obras e sua realidade local.

As exibições eram entendidas, portanto, em uma lógica de pesquisa e mobilização comunitária, abrindo caminho para uma discussão mais coletiva sobre os problemas de cada lugar, o que contribuía no roteiro dos filmes a serem realizados. Em todos os momentos de formação nas comunidades, um tema bastante trabalhado era como desenvolver as ideias dos jovens e abordar suas temáticas de interesse, a conexão destas com os desafios, possibilidades e limites de suas comunidades e, também, sua viabilidade de realização em um projeto de audiovisual.

A dinâmica de realização dos textos de roteiro, articulando som, imagem e texto, em cada comunidade contemplou a noção do roteiro de documentário como um processo investigativo. Estabeleceu-se um roteiro de filmagens como uma espécie de guia para as gravações, de caráter flexível, e um roteiro de montagem, em que se formula a síntese em outra sequência de todas as gravações e os materiais complementares trazidos para a edição. Junto a esses dois roteiros, a equipe trabalhou pedagogicamente com o processo de desenvolvimento de tema, argumento - como a forma de abordar o filme em construção - e objetivos a serem trabalhados com o filme com especial atenção às entrevistas.

Após longo debate entre a equipe do projeto, considerando os objetivos iniciais, as primeiras formulações de método, as ações desenvolvidas em Tempo Universidade e nas frentes de Tempo Comunidade, e os limites enfrentados no decorrer do percurso, os formadores chegaram em outubro de 2012 à seguinte síntese frente aos propósitos pedagógicos e estéticos com o processo formativo:

- autonomia na produção audiovisual: domínio de todas as etapas de produção de um documentário;

- compreensão do potencial da linguagem audiovisual para a vida do estudante e da comunidade rural em que vive;

- uso da linguagem como forma de pesquisa em processo: considerando a atuação do integrante do projeto como professor e pesquisador em formação. (UNIVERSIDADE DE BRASÍLIA, 2012, p. 2)

\section{Resultados e reflexões do percurso}

Foram realizados, a partir deste processo de oficinas, cinco filmes: O Antes do Agora, no Assentamento Virgilândia, em Formosa (GO) e Conquistar a terra, produzir o pão, em um préassentamento do Movimento de Apoio ao Trabalhador Rural (DF), tratam da questão agrária, com enfoque nos conflitos com o agronegócio e a especulação imobiliária, bem como as perspectivas de produção agroecológica; Império e suas raízes, realizado nas comunidades quilombolas Kalunga em Cavalcante (GO) e Juventude rural: tradição e mudança no Projeto de Assentamento Banco da Terra em Buritis (MG) trazem o tema das manifestações culturais de seus territórios e a relação destas com os moradores locais, especialmente a juventude; por fim, o filme Brigada Semeadores, do Assentamento Pequeno William, em Planaltina (DF) aborda um coletivo de teatro político no MST com larga trajetória. 
Em linhas gerais, certamente as obras expressam a busca pela apropriação da linguagem audiovisual, com limites como a demanda de maior desenvolvimento em propostas estéticas e acabamento técnico. Contudo, acreditamos que é importante destacar que as obras revelam o potencial do processo de pesquisa gerado com os filmes e a concepção da iniciativa em uma dinâmica de mobilização comunitária. Emerge de forma evidente, a nosso ver, a força da autorrepresentação dos estudantes realizadores de audiovisual e das comunidades retratadas nos personagens de seus filmes, revelando uma relação humana de trocas e autoreconhecimento que se associa no modo de produção coletivo e, certamente, passou para a tela e aos espectadores.

Essas obras constituíram um dos resultados finais do percurso formativo, sendo exibidas na atividade de encerramento do projeto, a Mostra Terra em Cena e na Tela: produção teatral e audiovisual da Educação do Campo da UnB. Intercalando debates, minicursos, oficinas, apresentações de peças teatrais e exibição dos cinco filmes do projeto em quatro dias na Faculdade UnB Planaltina, no ano de 2013, a mostra proporcionou um espaço de reflexão fecundo aos participantes do projeto. Estavam em pauta naquele momento questões-chave para a continuidade do trabalho com as linguagens artísticas na $\mathrm{LEdoC} / \mathrm{UnB}$, levando em consideração a experiência concreta na linguagem audiovisual desenvolvida pelo projeto e pensando sua relação com o trabalho desenvolvido já a mais tempo com a linguagem teatral dentro do curso, ou seja, como articular uma perspectiva de letramento articulado entre as linguagens teatral e audiovisual.

Quanto à realização da mostra, podemos entendê-la além de um espaço de formação e reflexão dos estudantes com incidência nos rumos do trabalho com as linguagens no curso. A presença de uma atividade cultural deste porte na UnB Planaltina teve uma contribuição efetiva na consolidação do campus como espaço cultural e artístico, reforçando os vínculos com as comunidades participantes do projeto que trouxeram seus representantes à mostra, vendo as peças e filmes de seus territórios e das outras comunidades. Um processo de trocas continuadas de saberes entre universidade e comunidades, inclusive, uma vez que os filmes produzidos no projeto também foram exibidos em cada um dos locais de realização como parte do encerramento das atividades. $\mathrm{E}$ a própria ideia de mostra teatral e audiovisual ali criada teve continuidade em três edições posteriores (2017, 2018 e 2019), demonstrando esse potencial de articulação, inclusive ampliado na última edição para a Licenciatura em Educação do Campo da Universidade Federal do Piauí.

Retomando à questão do letramento audiovisual realizado no âmbito do projeto, é fundamental retomar e interpretar os três aspectos que nortearam o processo formativo, elencados anteriormente: autonomia na realização audiovisual, compreensão do potencial da linguagem e entendimento do audiovisual como pesquisa em processo.

A autonomia dos estudantes como realizadores, em diálogo com a ideia de transferência dos meios de produção audiovisuais, marcou o projeto desde o início e esteve presente nas suas formações e metodologia. Porém, é importante ressaltar que, embora a concepção e a prática de formação fossem claras nesse aspecto, dois limites incidiram de forma contrária: o pouco tempo para apropriação dos equipamentos e técnicas do trabalho com o audiovisual e, em relação com isso, a centralização do processo de edição dos filmes em dois montadores-formadores.

Esse afunilamento do processo de edição numa centralização em pessoas que dominam a técnica é comum em projetos de formação no audiovisual. Cirello ressalta que "os coordenadores e educadores, em geral, conceitualmente prefeririam que a operação fosse feita pelos alunos" (2010, p. 175), mas fatores como o volume de material bruto e a qualidade em que este foi filmado, o ritmo de trabalho na edição para adequar-se aos prazos e uma sensação de impotência dos educandos ao lidarem com uma ferramenta complexa como softwares de edição de vídeo, que envolvem um lento aprendizado, incidem em sentido contrário

Uma alternativa seria encontrar processos pedagógicos específicos voltados para isso, preservando uma relação democrática centrada no debate de ideias durante a montagem. Um 
exemplo neste projeto de uma relação desta natureza ocorreu na edição do filme Brigada Semeadores. Adriana Fernandes, realizadora que acompanhou a edição junto com a montadora Adriana Gomes, relata que foi "privilegiada, porque pela teimosia da Adriana Gomes consegui me apropriar de uma linguagem que eu desconhecia. Conheci o pessoal do Mídia Independente, conheci os softwares de edição. Conseguimos envolver a comunidade, trabalhar coletivamente" (WOLFF et al., 2013, p. 57).

Nesse depoimento de Fernandes, percebemos também o potencial da linguagem audiovisual, sobretudo na relação entre a apropriação da linguagem e o fortalecimento de processos coletivos. Gideão Gomes, um dos realizadores do filme $O$ antes do agora, aponta que o audiovisual possui um forte potencial a ser explorado por todos, sendo que um dos caminhos para que isso ocorra é "que todas as escolas pudessem ter uma disciplina voltada para a linguagem audiovisual, que trabalhasse de forma coerente o que verdadeiramente é o audiovisual, e não como funciona hoje em dia" (WOLFF et al., 2013, p. 34). Gideão, em sua reflexão, ressalta o caráter de "recurso didático de segunda ordem" (DUARTE, 2009, p. 71) comum ao uso do audiovisual na escola.

Para o reconhecimento do potencial da linguagem em sua relação com a escola e, especialmente o letramento escrito, um caminho é apontado pelo grupo do filme Juventude Rural. Ao entenderem a linguagem como parte relevante do múltiplo letramento a ser trazido para a forma escolar, superando o antagonismo com a forma escrita e a forma verbal, a equipe elaborou a seguinte reflexão: "trabalhamos os diversos modos de letramentos e valorizamos todos eles, diversificando as formas de ensino e aprendizado. Aprendemos a manusear a filmadora, como trabalhar em coletividade. Tudo isto é forma de aprendizagem" (WOLFF et al., 2013, p. 34).

A percepção dos participantes do projeto da realização audiovisual como processo de pesquisa investigativo, com impacto direto na sua formação, era comum a todos, como indicam os documentos consultados. Um exemplo é o objetivo do filme Império e suas raízes no território Kalunga, que, ao focar nas romarias e manifestações culturais de comunidades de difícil acesso como o Vão do Moleque e o Vão de Almas, propunha "conhecer os significados e poder apresentar os romeiros e comunidades aos jovens que participam dessa manifestação cultural e sequer sabem o significado e seu surgimento" (WOLFF et al., 2013, p. 67). Ainda como investigação, em diálogo com os estudos realizados nas disciplinas de Tempo Escola, as estudantes realizadoras Kalungas mostram que estava em questão comparar como ocorriam essas manifestações culturais no passado e como se dão no presente, "no intuito de perceber as influências sofridas pela interferência da indústria cultural, ou seja, se essas comunidades ainda preservam a forma com a qual os seus antepassados manifestavam sua cultura" (WOLFF et al., 2013, p. 67).

Um exemplo da compreensão de participantes dessa iniciativa sobre o potencial do audiovisual na pesquisa, trazendo aspectos de diferentes letramentos, é a necessidade de duas estudantes da LEdoC/UnB e realizadoras de audiovisual dentro do projeto, retomarem em um Trabalho de Conclusão de Curso aspectos levantados com a produção de seus documentários. Ou seja, a prática do processo de produção do filme, envolvendo pesquisa, contato com a comunidade, realização e exibição, fomentou a pesquisa científica, que parte de um processo de práxis - teórico-prático - gerado na produção de um filme. O audiovisual, desta forma, não se remete a uma ilustração da pesquisa ou um mero complemento, e sim se constitui como parte fundamental de um movimento de ação e reflexão.

\section{Considerações finais}

Como vimos nos resultados do percurso, os debates sobre o sentido da formação em audiovisual nas oficinas e os acúmulos do processo expressados pelos filmes e sua exibição em uma mostra artística na Faculdade UnB Planaltina (FUP) também abriram consequências 
produtivas, incorporadas como acúmulo ao trabalho com as linguagens artísticas do audiovisual e do teatro. O amadurecimento da equipe ligada ao projeto, sobretudo após as exibições na FUP e nas comunidades, somada às rodadas de avaliação, levou à formulação de uma nova síntese sobre o trabalho com audiovisual na Educação do Campo, agora associada às funções deste trabalho.

Em linhas gerais, conforme documento da época, estabeleceram-se seis tópicos: a) qualificar a análise crítica da linguagem audiovisual, realizada pelos estudantes e egressos da LEdoC/UnB, combatendo os padrões hegemônicos de representação da realidade, operados pela Indústria Cultural, bem como estereótipos na representação dos povos do campo no cinema, televisão, publicidade, etc.; b) entender o audiovisual como um meio de elaboração da memória coletiva nas comunidades rurais, nas escolas do campo, nos movimentos sociais camponeses e quilombolas; c) potencializar a linguagem como recurso político de elaboração dos problemas e exposição de denúncias, atuando em frentes de conflito urgentes nos territórios, bem como instrumento organizativo local; d) compreensão do audiovisual enquanto recurso de pesquisa e elaboração de narrativas a serem utilizadas no trabalho escolar, criando seus próprios materiais didáticos em perspectiva de multiletramentos (ROJO, 2009) texto-som-imagem; e) estimular a fruição do legado da produção audiovisual e cinematográfica, entendendo o papel da arte como espaço de produção simbólica autônoma e elemento mediador para construção de nosso sentido de humanidade; f) ampliar as interfaces entre diferentes linguagens e seus letramentos como audiovisual e teatro, literatura e música, que podem ser potencializadas dentro e fora da sala de aula, por meio do trabalho articulado dos grupos teatrais dos estudantes com o audiovisual, da leitura de romances e da exibição e debate de suas adaptações para o cinema (WOLFF et al., 2013).

Entendemos que essa síntese das funções do trabalho com a linguagem audiovisual na Educação do Campo é um acúmulo fundamental para a consolidação dos esforços no letramento audiovisual, tanto para as licenciaturas na formação inicial de professores, como nas próprias escolas do campo e suas comunidades. É importante destacar que esta formulação se tornou possível por conta de um largo percurso audiovisual, com inúmeras contribuições de educadoras/es, estudantes e participantes das comunidades em torno de um mesmo projeto apoiado pelo poder público.

A qualidade da reflexão em torno deste percurso audiovisual, envolvendo diferentes dimensões estéticas, políticas, organizativas e pedagógicas do trabalho com o audiovisual, trouxe também a convicção para os professores da LEdoC/UnB da necessidade de estruturar o trabalho com a linguagem audiovisual no curso. As condições para a efetivação disso ocorreram pouco tempo depois do fim do projeto, com a reformulação do Projeto Político Pedagógico do curso (PPPC), iniciada em 2014 e que levou a um novo arranjo da matriz curricular. Sendo assim, "diante deste quadro e da demanda crescente de compreensão e conhecimento técnico da linguagem audiovisual e das artes plásticas decidimos proceder com a substituição da linguagem musical pelas artes visuais e artes do vídeo" (UNIVERSIDADE DE BRASÍLIA, 2018, p. 24), com o intuito de reforçar diferentes conexões. Entre elas, foram previstas, conforme o PPPC, "o trabalho com múltiplos letramentos que a área de Linguística já desenvolve, enriquecendo o trabalho com a possibilidade de trabalho com as artes visuais e com o audiovisual" (Ibidem, p. 24) e "a formação de professores da área de Linguagens o estudo das influências da Indústria Cultural na sala de aula e, em espaços outros, por meio da análise da articulação entre as esferas da cultura, da política e da economia" (Ibidem, p. 24-25).

Entre tantas trocas de saberes, acúmulos para uma licenciatura em Educação do Campo em construção e experimentos produtivos em múltiplos letramentos, para concluir este artigo queremos ressaltar dois aspectos deste percurso audiovisual. Percebemos que processos de longo prazo como o projeto aqui descrito e analisado, podem ter uma contribuição de fomentar nas escolas do campo e comunidades próximas uma cultura política de debate a partir do 
audiovisual, desde que esta seja estimulada com uma ação pedagógica. Temas que emergem de uma sensibilização por meio do audiovisual podem funcionar como uma porta de entrada para uma reflexão que se estenda da realidade tratada no filme à realidade local e, evidentemente, serem aprofundados por outros letramentos como o escrito e a pesquisa em meios digitais.

Outro aspecto que destacamos, por fim, é a percepção vinda de que as experiências, ao serem problematizadas coletivamente durante sua realização e sistematizadas posteriormente, têm uma contribuição direta na construção de um método de trabalho com a linguagem, caracterizado como processo pedagógico e criativo e, sobretudo em nosso contexto, afinado com os princípios e métodos da Educação do Campo. Como vimos neste artigo, a equipe de coordenação pedagógica e de formadores na linguagem audiovisual não tinha uma concepção fechada sobre o sentido da práxis formativa e sim a construiu ao longo do percurso, chegando a formulações distintas, embora complementares, e que nos servirão certamente para as experiências em andamento ou às que virão.

\section{Referências}

CIRELlO, Moira Toledo Dias Guerra. Educação Audiovisual Popular no Brasil - Panorama 1990-2009. 2010. 361 f. Tese (Doutorado) - Programa de Pós-graduação em Estudo dos Meios e da Produção Mediática, Escola de Comunicação e Artes, Universidade de São Paulo, São Paulo, 2010.

DUARTE, Rosália. Cinema \& Educação. Belo Horizonte: Autêntica Editora, 2009.

GONÇALVES, Felipe Canova. Linguagem audiovisual e Educação do Campo: práxis e consciência política em percursos audiovisuais. 2019. 290 f., il. Tese (Doutorado em Comunicação) - Universidade de Brasília, Brasília, 2019.

MARTINS, Aracy Alves; TEIXEIRA; Inês Assunção de Castro; MOLINA, Mônica Castagna; VILLAS BÔAS, Rafael Litvin. Outras terras à vista: Cinema e Educação do Campo. Belo Horizonte: Autêntica, 2010.

ROJO, Roxane. Letramentos múltiplos, escola e inclusão social. São Paulo: Parábola, 2009.

SOUSA, Rosineide Magalhães de. Letramentos na Licenciatura em Educação do Campo: transitando no contexto acadêmico. In: ARAÚJO, Júlio (Org.). Gêneros e letramentos em múltiplas esferas de atividade. Campinas-SP: Pontes Editores, 2016. p. 69-94.

UNIVERSIDADE DE BRASÍLIA. FACULDADE UNB PLANALTINA. Projeto Político Pedagógico do Curso de Graduação em Licenciatura em Educação do Campo. Planaltina, DF, 2018.

UNIVERSIDADE DE BRASÍLIA. FACULDADE UNB PLANALTINA. Projeto: Formação de Educadores do Campo para uso de Tecnologias de Informação e Comunicação, para análise e produção audiovisual e trabalho com juventude rural no Centro-Oeste. Planaltina, DF, 2011.

UNIVERSIDADE DE BRASÍLIA. FACULDADE UNB PLANALTINA. Relatório Trimestral de Acompanhamento da Execução das Atividades: Formação de Educadores do Campo para uso de Tecnologias de Informação e Comunicação, para análise e produção audiovisual e trabalho com juventude rural no Centro-Oeste. Planaltina, DF, 2012. 
VILLAS BÔAS, Rafael Litvin. Educação do Campo, questões estruturais brasileiras e Formação de Professores. In: MOLINA, Mônica Castagna; SÁ, Lais Mourão (Org.). Licenciaturas em Educação do Campo: registros e reflexões a partir de experiências piloto. Belo Horizonte: Autêntica, 2011. p. 307-318.

WOLFF, Eliete Ávila et al. Relatório Final do Projeto: Formação de Educadores do Campo para o Uso de Tecnologias de Informação e Comunicação. Planaltina: Faculdade UnB Planaltina, 2013. $165 \mathrm{p}$.

\section{Sobre o autor}

Felipe Canova Gonçalves: Professor de Audiovisual e Artes na Licenciatura em Educação do Campo, campus UnB Planaltina. Doutor em Comunicação pela UnB. Integra o Grupo de Pesquisa Terra em Cena: teatro, audiovisual e Educação do Campo.

E-mail: canovagoncalves@gmail.com. 